\title{
REFUSING (MIS)RECOCNITION:
}

\author{
Navigating Multiple Marginalization \\ in the U.S. Two Spirit Movement
}

\section{INTRODUCTION}

In March of 2018, Two Spirit author Joshua Whitehead offered a generous withdrawal of his nomination for the Lambda Literary Award in the Trans Poetry category. In it, he argues:

To be Two Spirit/Indigiqueer, for me, is a celebration of the fluidity of gender, sex, sexuality, and identities, one that is firmly grounded within nehiyawewin (the Cree language) and nehiyaw world-views. I think of myself like I think of my home, manitowapow, the strait that isn't straight, fluid as the water, as vicious as the rapids on my reservation, as vivacious as a pickerel scale. I come from a nation that has survived because of sex and sexuality, as post-contact nations that deploy sex ceremonially. My gender, sexuality, and my identities supersede Western categorizations of LGBTQ+ because Two Spirit is a home-calling, it is a home-coming. I note that it may be easy from an outside vantage point to read Two Spirit as a conflation of feminine and masculine spirits and to easily, although wrongfully, categorize it as trans; I also note the appropriation of Two Spirit genealogies by settler queerness to mark it as a reminder that Western conceptions of "queerness" have always lived due in part to the stealing of third, fourth, fifth, and fluid genders from many, although not all, Indigenous worldviews. (Whitehead).

In this statement, Whitehead articulates many of the issues Two Spirit ${ }^{1}$ people, or Indigenous North Americans who identify

1. Epple (1998) critiques terms such as berdache, gay, alternate gender, and Two Spirit within academia, warning that "while the term 'Two Spirit' offers many benefits [...] its adoption by academia as a generic label should be carefully evaluated" $(1998,274)$. In this article, however, the term is used because it is the one that my study participants and the larger community choose to use for themselves.
Jenny L. Davis Dept. of Anthropology University of Illinois, Urbana-Champaign USA 
Indigenous Social Movements in the Americas as spiritually both female and male, face. Specifically, Two Spirit individuals are often represented in media and academic research primarily in terms of colonial binaries of sexuality or gender-a perspective that overlooks the equal importance of both axes of identity, as well as the primary importance of Indigenous identity. These widely circulating discussions about Two Spirit people have often uncritically assumed that Two Spirit in-group use of terms such as gay, lesbian, bisexual, transgender, and queer is synonymous with dominant understandings of those identities, failing to consider how Indigenous culture(s) in general, and discourses within Two Spirit communities in particular, have transformed the ways such terms are conceptualized and articulated. Consequently, people who identify as Two Spirit are frequently asked by researchers, media, and others outside of the community to position their identity as either female or male, and to define Two Spirit as either sexuality-based (e.g., gay) or gender-based (e.g., trans).

However, within the Two Spirit regional groups, gatherings, and individual life histories, there is no singular type of body, experience, sexual practice, styling, or cultural practice that universally maps to being Two Spirit. There never was. Even within a single Indigenous tribe, we know great variation existed across individuals and time periods, and the Two Spirit identity and movement bring these practices and experiences together across more than 500 nations and communities. The often preferred 'simple' or 'singular' answer to these questions erases the complexity of Two Spirit identity and highlights the problem of mis-recognition or "mistranslation" of differences that deeply affect and shape both Two Spirit experiences and outside (mis)understandings of the term, identity, and social movement. In this article, I focus on the discursive strategies within Two Spirit events and groups that center the definition of 'Two Spirit' first and foremost as an Indigenous identity by using both unifying/mass terms (Native American, glbtiq) and culturally \& community specific terms (specific tribe names, Two Spirit). Rather than selecting a 'right' term, such conversations highlight the constant, simultaneous positionings negotiated by Two Spirit people in their daily lives, and the tensions between recognizability and accuracy, communality and specificity, and indigeneity and settler culture, and the burden multiply 
marginalized people carry in negotiating between all of those metaphorical and literal spaces.

This "both/and" approach to gender and sexuality, and to femaleness and maleness, is echoed in a number of other binaries that Two Spirits face when negotiating their Indigenousness. For example, an individual might identify as both Navajo/Diné and Native American, or as nadhlé (one of the Navajo third- or fourth-gender categories) as well as Two Spirit. Within each these poles, individuals position their local identities in relation to the generalized categories into which they are often subsumed. I demonstrate that this positioning is accomplished through innovative uses of semantic 'adequation' and 'distinction' as defined by Bucholtz and Hall as well as through the deployment of Indigenous terminology for local identities during a public presentation by a regional Two Spirit group. The group's simultaneous identification with both "ends" of multiple binaries demonstrates the community specific and contextually bound nature of categories often perceived as binaries.

In this way, Two Spirit individuals utilize available categories of identity, not as either/or binaries but rather as overlapping concepts-differentiated along micro- and macro-scales- to refuse attempts to both reduce the Two Spirit identity to one that is based either in gender or sexuality, and the appropriation of the identity and movement by non-Indigenous individuals and groups within broader national and global queer movements. Here I draw on Audra Simpson's concept of the politics of refusal, which she outlines in her work on Mohawk political struggle and daily life and their struggles to articulate and maintain political sovereignty through centuries of settler colonialism. The politics of refusal, per Simpson, "stands in stark contrast to the politics of cultural recognition" while also standing as a rejection of anthropological assumptions that "that the colonial project is complete." Critically, she reminds us that political "recognition" places an emphasis on requiring tribes to express a specific version of cultural difference, or "otherness", instead of an autonomous one, independent from settler and colonial provisions (2014: 20). In other words, "recognition" still monitors cultural differences in a way that does not lead to equality but rather serves as a reaffirmation of how 
history has always been reported $(20,33)$. Refusal as a practice, methodology, and theory has proven to be an illustrative means of understanding actions-and intentional in-actions-in settler colonial contexts as well as other spaces and places of political hierarchy, oppression, and the responses to those oppressions.

\section{METHODOLOGIES}

This project draws on over a decade of research and utilizes mixed methodologies that include the long-term ethnography (participation/observation) of two Two Spirit organizations, multisited ethnographic participation at Two Spirit events and gatherings, and interviews with individuals who identify as Two Spirit or allies. This research has produced a large corpus of fieldnotes, audio and visual recordings, and media, which provide the data for my semiotically centered analysis of Two Spirit language and identity. It is also informed by my own personal experience as a Two Spirit person who participates in regional groups and gatherings, and who has worked as a co-director in two different Two Spirit societies. As such the individuals and community/ies under discussion include my local and digital social network(s), close friends, and in some cases, my adopted family.

While my research project spans throughout the United States and both public and private community contexts, the politics of refusal discussed in this article are perhaps most evident

Indigenous Social Movements in the Americas in moments of public visibility to non-Native segments of the U.S. population, when the contrast of difference between Two Spirit individuals and settler society are the most salient, and the implications of non-recognition due to those differences are the most tangible. As such, this article focuses primarily on the linguistic negotiation of Two Spirit identity during a public educational community presentation by the Rocky Mountain Two Spirit Group, ${ }^{2}$ which was sponsored by the Colorado Human Rights Campaign in honor of Native American Heritage Month, and interviews with Two Spirit individuals. In accordance with the agreements made with my research participants, all names used in this article are pseudonyms. The discursive tactics analyzed here are also

2. Pseudonym 
present in less contrastively marked situations, such as small group gatherings or in individual responses to interview questions; however, in these contexts there is a general assumption that the interlocutor(s) understand the general principles of Two Spirit identity, Native American histories and cultures, and lgbtq realities.

\section{HISTORY OF TWO SPIRIT IDENTITY AND MOVEMENT}

The concept of Two Spirit, sometimes problematically referred to as berdache, ${ }^{3}$ first entered the anthropological literature through discussions of three-, four-, and five-gender systems. ${ }^{4}$ Indigenous cultures throughout North America were frequently offered as examples of these social configurations, yielding a plethora of historical references to gender variance specific to these communities. However, rather than focusing on groupinternal conceptualizations of these configurations, much of this work is archival and focuses on groups as they were discussed in the historical record produced by European conquistadors, missionaries, and lay anthropologists dating as far back as the first arrival of Europeans on the continent (for historiographies of these accounts, see Callender and Kochems; Jacobs; Roscoe; Williams). These systems were of particular interest to anthropologists as examples of divergence from the Western binary of female/ male sociosexual roles.

Indigenous non-binary configurations of gender, sexuality, and kinship later gained greater prominence in sociological, anthro-

3. A multitude of anthropologists and Indigenous scholars have outlined the problematic nature of the term "berdache" (Driskill, et al.; Epple; Herdt; Thomas and Jacobs). It was first applied by French and Spanish colonizers based on their observations of the gender expression or sexual conduct of some Native Americans. In French, berdache means "kept boy" or "male prostitute" and is clearly laden with European prescriptions of morality and social mores. In summing up the arguments against this label, Blackwood notes that "the term 'berdache' is no longer acceptable in referring to Native American genders [...] because of its problematic origins; because it is a reminder of the imposition of colonial categories, morality, and values on Native ways; and because many Native American Two Spirits reject the term and choose to define themselves by their own terms" (287).

4. As opposed to binary gender systems that only recognize two gendersfemale and male-third- and fourth-gender categories exist in systems that recognize three or more genders. 
pological, and gender studies consciousness, The renewed attention to these social roles was not due to interest in models of gender variance per se, but due to a quest for examples of primordial homosexuality (and bisexuality, although this category was rarely discussed as such). Here, Two Spirit individuals, primarily (mis) understood as only men who had sexual intercourse with other men, provided instances of apparent historical acceptance of homosexuality as part of a larger endeavor of looking at same-sex desire in ancient Rome and Greece, Victorian England, and other societies. This conceptualization effectively re-framed Two Spirit identity as a matter of sexual orientation rather than gender identity. Indeed, two of the most cited texts on berdache identity, Walter Williams's The Spirit and the Flesh in 1992 and Will Roscoe's Changing Ones in 1998, while providing a valuable compilation of diverse realizations of gender variance in Indigenous North American societies, problematically frame these historically and culturally specific identities within the terms of a dichotomous gender system, conflating alternative gender practice with homosexuality.

The perspective presented by authors like Williams and Roscoe is further complicated by the fact that it mirrors the social definitions used by some Two Spirit people themselves-especially in the movement's beginnings. During the emergence of the largely white gay movement within the United States in the 1960s, a smaller movement was born: that of gay American Indians

Indigenous Social Movements in the Americas (GAI). As its name indicates, this group placed individuals squarely within a Western gay framework of homosexuality rather than emphasizing the gender diversity that has historically been central to Native gender and sexual alterity. In the 1990s, the Two Spirit movement formed, not necessarily counter to GAI and groups like it, but with a different emphasis and goal: to acknowledge the distinctive identities of individuals who might have been considered simply "gay Indians" within traditional, pre-contact Native culture(s). This movement co-occurred with increased interest from anthropologists and Native American Studies scholars who produced both ethnographic and archival based research, such as Jacobs et. al.'s, Two-Spirit People: Native American Gender Identity, Sexuality, and Spirituality and Sabine Lang's Men as Women, Women as Men: Changing Gender in Native American Cultures. 
Many of the Two Spirit groups that were founded in the United States in the early 1990 s received most, if not all, of their financial resources from government HIV/AIDS funding dedicated to outreach for 'MSM' (men who have sex with men) individuals. That funding aggressively limited use of those funds for anyone not deemed MSM by U.S. government standards-including at the early retreats and gatherings those groups organized (Jolivette 2016 \& Gilley 2006). As a result, the earliest gatherings were limited to those identified as male at birth, and the emerging norms of Two Spirit discourses were shaped by that limited participant set. However, some Two Spirit societies worked to subvert, or get around, these restrictions by asserting their own definitions of gender and sexuality and seeking funding from non-restrictive sources. As such, the number of people involved in Two Spirit organizations who identify more closely with broader categories of identified female at birth, trans, genderqueer, and gender-non-conforming shifted over subsequent decades-initially from groups that did not depend on federal health-based funding-thereby shifting the representation of who, and what 'Two Spirit' was.

Research on Two Spirit identity, practice, and activism has, over the past decade, received increased attention as well as the related areas of Queer Indigenous Studies, and Indigenous gender and sexuality. This research, conducted by Indigenous and non-Indigenous, Two Spirit/queer and not, has provided a glimpse of the impacts of HIV/AIDS within the Two Spirit community (Gilley; Jolivette; Morgensen), examined Indigenous gender and sexuality within both Native American and settler literatures (Tatonetti 2011, 2014, 2015; Rifkin 2011a, 2011b; and Scudeler), and theorized the legal and political realities, and the everyday lived experiences of Two Spirit or queer Indigenous people in the United States and Canada (see in particular edited volumes by Driskill et al.; Innes and Anderson; Barker; and vol. 16, no. 1-2 of JLO). This work has been matched, if not exceeded, in robustness by the production of Two Spirit fiction, poetry, memoir, performance, and art. ${ }^{5}$

5. A list of this work would far exceed the word limit for this article. Tantonetti, Heath Justice, and Driskill's 64-page "Two Spirit Bibliography" is an extensive compilation of these works, and (Drikill et al.'s Sovereign 
Today, Two Spirit organizations exist throughout the United States and Canada. Members of local groups generally come together for regular meetings, activities, and social events (potluck dinners, birthday parties, etc.) as well as for events in both the Native American community (such as powwows) and the queer community (such as Pride celebrations). Of perhaps equal importance to members, and to the creation and maintenance of the larger Two Spirit community of practice, are the regional and international gatherings held every few months, which are largely comprised of individuals from the United States and Canada, although participants from Mexico and New Zealand have been known to attend. In addition to these local and regional settings, participants often move between different Two Spirit communities in different regions over time, creating a strong network and sense of unity within local groups as well as across the larger national and international community.

Members of the Two Spirit community experience numerous and layered axes of marginalization. While they are most obviously marginalized based on their ethnicity and/or tribal affiliation(s) and gender and/or sexual expression, they also often lack the privileges afforded to those with middle and upper class economic status, access to education, and they face stereotypes surrounding rural and reservation life. Some within the group also experience marginalization based on disability and health status (including HIV stigma). As such, the space created at Two Spirit

Indigenous Social Movements in the Americas gatherings and events that centers on and celebrates Two Spirit experiences is not to be underestimated.

Two Spirit groups and gatherings, both local and national, are thus necessarily sites of multi-tribal group identity formation, bridging the temporal gap between historical and contemporary positionalities. Participants often highlight the differences between the various nations represented in these groups while simultaneously integrating their languages, traditions, and histories into a multi-tribal conceptualization of what it is to be Two Spirit. Hence, research on Two Spirit identity not only broadens scholarly understanding of the intersection between articulations of gender,

Erotics and the Gay American Indians' Living the Spirit are notable anthologies of Two Spirit authors. 
sexuality, and indigeneity, but also reveals how Two Spirit groups create and adhere to a conceptualization of "Indian" as a racial and ethnic identity that maintains continuity with the past even while observing and engaging in radical reformulation of Indigenous cultures.

Discussions of Two Spirits that emphasize commonalities between this identity and the generalized concepts of either "gay" or "trans" often lose sight of the more localized aspects of Two Spirit identity that hold primary importance for many groups and individuals. The term Two Spirit was self-selected in 1990 at the Third annual intertribal Native American/First nations gay and Lesbian gathering in Winnipeg, Canada, based on a calque of many tribal terms, which translate to "of two (i.e., female and male) spirits." This term was chosen to fulfill two functions: first, to replace the highly problematic colonialist term berdache, which was previously used throughout anthropology and related fields for Native American third- and fourth-gender roles; and second, to provide a new term that might encompass all of the localized realizations of Indigenous gender and sexual variance in North America. The decision to coin an entirely new term is significant: participants shifted away from the newer collocation "gay Indian", which had been used by many in the community previously, as well as the terms associated with gender variance within a specific tribal nation (e.g., Navajo nadhlé, Lakota winkte).

\section{BINARY IDENTITIES IN A TWO SPIRIT PRESENTATION}

\section{TRIBAL AFFILIATION VERSUS NATIVE/INDIAN}

In his 2006 book Becoming Two Spirit, Brian Gilley objects to the claim made by some theorists that those who participate in pan-Indian sites have little or no connection to their tribal communities. While he acknowledging that "Two Spirit is intended to be a multi-tribal identity," Gilley also emphasizes that this identity "is used to reference tradition" (33). A contemporary multi-tribal identity is thus constantly juxtaposed with individual tribal connections and traditions. This juxtaposition was evident in a presentation of Two Spirit identity during an educational community presentation by the Rocky Mountain Two Spirit group in November of 2006, which was sponsored by the Colo- 
rado article of the Human rights Campaign in honor of Native American Heritage Month. The group started off the presentation with a song, which was followed by individual introductions, an overview of the meaning and history of Two Spirit identity, and finally ended with a question and answer period. The group members presenting included a range of tribal affiliations including Lakota, Navajo, Jicarilla and Chiricahua apache, Pueblo, Osage, Eastern Band Cherokee, and Chickasaw. During the presentation, group members collectively described themselves as "Indian" and "Native American" while simultaneously emphasizing their individual community backgrounds both directly and indirectly.

One of the most salient ways in which members of Two Spirit groups highlight their own community backgrounds is through the use of tribal languages in self-introductions during educational presentations for various communities and audiences, both Native and non-Native, using Indigenous languages in a multitribal context allows speakers to engage in a process of adequation, or the creation of "sufficient similarity" (Bucholtz and Hall 495), between tribal identity and more general Native identity, while simultaneously engaging in distinction, or the construction of difference, among the various nations represented. Each instantiation serves to authenticate the language user as Indigenous as well as a citizen of a local tribe or nation and, as Ahlers (2006) notes, establishes the entirety of the presentation to follow as Native

Indigenous Social Movements in the Americas discourse by functioning as an identity marker. That is, the ability to speak one's heritage language (whatever that language might be) is a strong authenticator of Native community membership, while using a language that is recognizably different from others used in the same context highlights differences between the tribal communities represented, an act of distinction.

The invocation of distinction in order to problematize the macro-category Indian was accomplished at several moments in the presentation, especially during the introductions and personal narratives. As part of the beginning of the ceremony, each of the group members introduced themselves, providing several points of information, including name, tribal affiliation, and length of time with the group. Five of the eight group members used their tribal language in these introductions, with only one provid- 
ing a translation in English; importantly, there was no expectation that another speaker of any of these languages was present. This use of tribal languages not only established the group as separate from its non-Native audience, but also underscored distinctions between individual group members, particularly because the languages used-Navajo/Diné, Mescalero Apache, Jicarilla Apache, Laguna Pueblo, and Lakota-were perceptibly different even to an unfamiliar listener. The incorporation of Indigenous languages into the introductions is especially significant given the claim that "the decline in 3rd/4th gender roles paralleled the decline in Native language use" (Gilley 33). Since Indigenous language use is largely associated with the maintenance of tradition, the presenters' use of their tribal languages demonstrated not only an alignment with maintaining or reviving the traditional but also their connection with their tribal communities (Davis 67-68).

The multiplicity of stances regarding tribal unity and differentiation was also found within community disagreements regarding the choice of the term "Two Spirit," which appears to erase local affiliations in favor of a multi-tribal identity. This debate arose early during the community presentation, when leaders of the group were offering brief definitions of the term "Two Spirit" as well as its history. In excerpt 1, lines 4 and 5, a participant named Eric critiques the term as inadequate because of its "universal" and "generic" nature:

\section{Excerpt 1}

1. Eric: I'd like to refer back to what he said about

2. what it means to be Two Spirited

3. you know what Meg talked about earlier

4. about Two Spirited people was a universal term

5. just like Native American is a generic universal term

6. To... to distinguish you know Indians now

7. Because Native American

8. American Indian

9. Native American

10. so you can youse the term interchangeably

11. 'Cause you know

12. if you want to be correct you'd call us by our tribe

13. but it's impossible for you all to see 
By comparing the term Two Spirit to the similarly unsatisfying (to them) term Native American, Eric points out how both labels fail to acknowledge the different backgrounds of those they encompass. Eric's preference for more specific designations is seen in line 12, in which he suggests that the "correct" form of address would be to label each individual by their specific tribe. At the same time, Eric does not admonish the audience for failing to use the preferred terminology, pointing out that "it's impossible for you all [i.e., non-Natives] to see," as non-Native individuals are not expected to be aware of the various characteristics that are associated with individual tribes (typical physical characteristics, differences in styling, common names, etc.).

Jackson (45) explains this issue within general conceptualizations of pan-Indian activities and groups: "Pan-Indianism assumes that individuals or groups engaging in social gatherings across tribal or national boundaries will increasingly lose their cultural distinctiveness [...] but it also ignores the capacity of communities to consciously maintain distinctive practices in interactionally complex settings." Assumptions surrounding pan-Indian groups and identities therefore set up a binary in which individuals are Indian either because of their connection to their distinctive tribal heritage or through their alignment with a cross-national (and hence culturally detached) identity, but not both. Ahlers (59) notes the same tension between individual tribal affiliation(s)

Indigenous Social Movements in the Americas and the more widely encompassing terms Indian, Native American, and American Indian in multitribal settings not unlike the Two Spirit presentation discussed here: "in intertribal settings, speakers may use a tribal designation in addition to the broader 'Indian.' Such shifting references reflect the shifting identity roles performed, and created, by Native Americans in their daily lives." She goes on to argue that, while this conflict between individual tribal identity and the broader category of Native American or Indian is no doubt especially relevant in multitribal settings, even as "these two identities are sometimes in competition, they also provide mutual support for one another" (59).

Crucially, the act of aligning with one's individual tribal affiliation in the group presentation both through explicit labeling in discourse and through the use of Indigenous languages did 
not challenge the speaker's authenticity in the larger category of Indian or Native American; rather, it strengthened this membership because it created an even sharper distinction between those speaking Indigenous languages on stage and the English-speaking audience. This phenomenon can be seen as an example of fractal recursivity, or the "projection of an opposition, salient at one level of relationship, onto some other level" (Irvine and Gal, 38). In other words, the differences between tribes were highlighted and oppositional only when compared to each other; they became mitigated and backgrounded when contrasted with a non-Native audience.

TRIBALLY SPECIFIC TERMS VERSUS TWO SPIRIT

Just as the specific tribal affiliation of each member was emphasized in the presentation, so too were the specific tribal roles associated with people who are Two Spirit, or spiritually both female and male. As each person presented their personal narrative about being Two Spirit, they most also employed the term or terms used in their own tribe's language(s) for that role. For instance, Brent, who was the youngest member of the group and was also seen as one of the most visible and politically active members, began his narrative by introducing the dine term nadhlé. In excerpt 2, after referring to himself several times as nadhlé, Brent directly addresses his decision to use the tribal term rather than the multi-tribal term Two Spirit.

\section{Excerpt 2}

Brent: that is actually one of the biggest misconceptions.

On the reservations

(.3)

all these tribes actually had names for

Two Spirit

people.

but how people see them as

just like "oh they just mean gay" but there is a deeper

root

((cough))

Brent: um that um for nadhlé

I'm sorry I say nadhlé more than I say Two Spirit

Cause

I (hhh)'m just stubborn that way 
This comment is framed as an apology. Brent's justification, "cause I'm just stubborn that way," indexes a belief that the community-specific term is an automatic or even natural way of referencing himself, as opposed to the more generalized term Two Spirit. His reluctance echoes Epple's critique of the broad application of terms such as berdache, gay, and even Two Spirit, which, she argues, are devoid of cultural and temporal grounding. Epple suggests that these "current analytical concepts simply do not accommodate the simultaneous distinctness (identity as nádleehí [plural]) and fluidity (identity as context-dependent) of nádleehi's self-descriptions" (268). Similarly, during the presentation when group members offered accounts of specific historical figures now included under the Two Spirit umbrella, they referred to such figures not simply as Two Spirit, but also with the term specific to that individual's tribal affiliation: for instance, winkte (Lakota), nadhlé (Navajo), and Ihamana (Zuni). Individuals in the group were thus very attentive to using the appropriate tribally specific designation for historical figures as well as for themselves and other group members.

However, while the members emphasized these tribally specific terms and roles that applied to themselves and others, they did so as members of the regional Two Spirit group rather than, say, an organization comprising solely individuals from their specific nations, and each strongly identified as Two Spirit in ways that were relevant to their daily lives. Despite the importance placed on local Indigenous identity labels, this in no way contradicts the appropriateness of 'Two Spirit' as another facet of these speakers' identities. In fact, the mutual dependence of local and multi-tribal terms could be observed in this setting precisely because presenters were recognized as Two Spirit and could also articulate their identity as winkte, nadhlé, and so on.

Here is it clear that the refusal to use only one term within an array of available terms, especially only those terms that are recognizable on a macro scale, is a strategic move toward being seen on multiple scales and levels. However, this move away from terms deemed not-specific-enough, or oversimplified does not refuse such terms all together, but rather generates the possibilities 
for multiple terms and categories to be applicable at the same moment, for the same person or group of people.

\section{TWO SPIRIT VERSUS QUEER}

In addition to specifying appropriate tribal labels for the Two Spirit identity of particular individuals, individuals identifying as Two Spirit were also very interested in distinguishing between the Two Spirit identity and gay, trans, or queer Indian during interviews, even though most aligned themselves with one or more of these categories. 'Cay/Trans Indian' and 'Two Spirit' are often presented as synonyms both in anthropological works (Gilley; Roscoe) and in discourses within the broader queer community. However, even gay-identified Two Spirits emphasize that these terms are far from synonymous.

One way that scholars and media representations create adequation between Two Spirits and queer individuals is by highlighting the cultural and spiritual similarities between Native Americans who identify as gay or lesbian and those who occupy what were historically recognized by their tribes with gender roles beyond binary gender systems. Once these groups have been established as similar enough to collapse into a single category, gay Indians are further adequated with the non-Native gay and lesbian population in the United States. In the first of these two steps, differences in gender identity are erased to highlight racial similitude, while in the second step ethnicity is erased to highlight the sameness of sexual orientation By referring to the historical and modern identities by the same term, Two Spirit, and then positioning that term as interchangeable with 'gay Indian', scholars adequate Two Spirit identity with being gay. This system of categorization is enabled by a focus solely on those members of the community who identify as gay and male; such research leaves out community members who identify, in relation to being Two Spirit, as trans, intersex, or genderqueer, in addition to, or apart from, identifying as homosexual or bisexual. Such thinking effectively erases the gender component of Two Spirit identity by excluding from this discussion the divergent ways that being Two Spirit may be embodied. 
Just as the Two Spirit group used terms such as Indian or Native American to identify with a larger ethnically marginalized community, so too they used terms like gay, intersex, transgender, and queer to position themselves within a wider community marginalized for gender or sexual alterity. As part of group members' recognition of various forms of gender and sexual non-normativity, they also adequate all of the terms within the Igbtiq acronym as semantically similar not only to each other, but also to their definition of Two Spirit.

One Two Spirit activist in their mid-30s living in California, Alex, regularly used gay as a term that worked to describe herself, explaining how she understood her place within her community by talking about their creation story in which the first humans that were created were Two Spirit. While telling this story, Alex used the terms transgender, intersex, and Two Spirit interchangeably to describe that first human. The semantic differences across these terms, which in dominant queer discourses are used to describe distinct realizations of gender and sexuality, are thus erased in this narrative, as are other discussions of what Two Spirit means. Instead, Two Spirit individuals frequently employ all of these terms more or less synonymously in order to highlight what they hold in common: gender and sexual identity outside of a binary norm. Thus, while the term Two Spirit is used to unify members with divergent tribal affiliations, it is also used as an overarching

Indigenous Social Movements in the Americas term for a more generalizable sexual and gender alterity, subsuming within its semantics gay, intersex, and transgender identities.

This semantic adequation may not seem so striking given that these same terms are often adequated to some extent under the acronym lgbtiq and its variants, or umbrella labels like queer. However, scholars within queer studies have demonstrated that this assumption of equivalence fails to describe the realities in which these larger adequations occur (e.g., Edelman; Zimman). In reality, resources and endeavors that purport to serve the entire range of people encompassed by the acronym have been shown, at best, to privilege gays and lesbians at the expense of transgender, genderqueer, intersex, and others' political and social needs and, at worst, to reinforce the subjugation of these latter groups. Thus, the adequation of these various identities both with one another 
and with the concept of Two Spirit demonstrates a different conceptualization of all of these terms. Of course, Two Spirits' attempts at adequation do not exist in a vacuum and may be seen as reinforcing mainstream ideologies about gender and sexual variance that fail to distinguish between groups that experience their identities in quite different ways. At the same time, the always growing participation of a number of trans, intersex, and genderqueer individuals in this and other Two Spirit groups suggests a willingness to set aside differences that are relevant in a non-Native context in order to emphasize the diversity of how Two Spirit identity is manifested. As Epple (274) notes in regard to the term Two Spirit: "it is little wonder then that a Native American category, such as 'Two Spirit,' requires only that one be both male and female, and Native American. The sexual, gender, or other manifestations of one's Two Spiritedness are understood to vary as widely as humanity itself." This ability to identify oneself as both queer and Two Spirit while emphasizing how the labels are far from synonymous exemplifies the approach many Two Spirit individuals take to binaries.

Two Spirit individuals and activists, thus frequently switch between these two levels of designation-and provide metacommentary about them, as Eric and Brent both did (excerpts 2 and 3, respectively). In doing so, they demonstrate the tension that exists between the preferred, more specific categories that Two Spirit individuals use to describe themselves and the likewise applicable, and often more easily recognized, macro-categories that connect them to others outside their immediate communities. Rather than treating this tension as a matter of irreconcilable dissonance, however, they embraced both local and dominant identity categories by grounding both in their indigeneity, and thereby demonstrated exactly what it means to occupy the murky "both/and" space that encompasses both poles of a binary. When Eric commented that "if you want to be correct you'd call us by our tribe, but it's impossible for you all to see," he highlighted that what is "correct" - recognizing and addressing the individual tribal heritages of each speaker - is also "impossible." Moreover, this conundrum is routinely expressed by Two Spirit activists; for those who embody both female and male, it is this very dissonance that characterizes 
Two Spirit experience. Driskill, et al. make an analogous argument about the combined use of the terms queer and Two Spirit, suggesting, "When linked, queer and Two Spirit invite critiquing both heteronormativity as a colonial project, and decolonizing Indigenous knowledge of gender and sexuality as one result of that critique." Based on my own research, I argue that the dichotomies found in each of the axes of identity negotiated by the Two Spirit individuals in interviews and presentations are not necessarily in conflict but rather may simultaneously function to partially represent a complex, multiply marginalized identity.

\section{CONCLUSION}

In the negotiation of a multiply marginalized identity such as Two Spirit, any unified imagining of identity is fractured by a strategy of emphasizing individual aspects of identity that may not be shared by fellow community members as well as occasionally adopting contradictory categories. This strategy redefines macroidentities like Native American, Two Spirit, and gay as necessarily made up of multiple, very different pieces-a mosaic-rather than as a homogenized identity that means the same thing, and is experienced the same way, by each person who aligns with it. As Simpson notes, in settler colonial societies, inclusion or recognition:

Indigenous Social Movements in the Americas

is only performed, however, if the problem of cultural difference and alterity does not pose too appalling a challenge to norms of the settler society, norms that are revealed largely through law in the form of decisions over the sturdiness, vitality, and purity of the cultural alterity before it.

A politics of refusal, then, may occur anytime an individual or group refuses "recognition" only as dictated by a colonial gazeat the expense of their own definition of themselves. In other words, Two Spirit, as a movement and identity, refuses the "gifts" of "citizenship" and recognition of mainstream glbtiq citizenship (and therefore aspects of citizenship of the state to the extent that glbtiq rights and experiences are managed and policed through state-apparatuses). I argue that the politics of refusal in Two Spirit activism and practice are many, but I have highlighted here 
two of the most prominent: first, the refusal to be recognized as Native if Indians are only heterosexual and cisgender, and second, the refusal to be recognized as queer if queerness is understood as inherently White (or defined through colonial frameworks).

As I have demonstrated, the Two Spirit group members in my research distinguish between the localized nature of their Two Spirit identity and the generalized categories into which that identity is often placed. The more localized aspects of identity-among them individual tribal affiliation and the specific responsibilities historically associated with Two Spirit people in their particular communities-were clearly integral to the group's definition of themselves. Yet these individuals' use of non-Native terminology-the generalizing Native American/Indian, Two Spirit, and queer- were not used simply as a compromise to reach non-Native audiences; rather they signaled multiple levels of community membership, each of which genuinely represented one part of these speakers' sense of themselves. In doing so, they bridge local, tribally specific understandings of Indigenous gender variance with wide-ranging contemporary discourses of sexuality and multitribal identity, reflecting the complex ground on which Two Spirit people stand. 
WORKS CITED

Ahlers, Jocelyn C. "Framing Discourse: Creating Community Through Native Language Use." Journal of Linguistic Anthropology, vol. 16, no. 1, 2006, pp. 58-75.

Anderson, Kim, and Robert Alexander Innes, editors. Indigenous Men and Masculinities Legacies, Identities, Regeneration. University of Manitoba Press.

Barker, Joanne, editor. Critically Sovereign Indigenous Gender, Sexuality, and Feminist Studies. Duke University Press, 2017.

Blackwood, Evelyn. "Native American genders and Sexualities: Beyond Anthropological Models and Misrepresentations." Two Spirit People: Native American Gender Identity, Sexuality, and Spirituality, edited by Sue-Ellen Jacobs, Wesley Thomas, and Sabine Lang, University of Illinois Press, 1997, pp. 284-296.

Bucholtz, Mary, and Kira Hall. "Theorizing Identity in Language and Sexuality Research." Language in Society, vol. 33, no. 4, 2004, pp. 469-515.

Callender, Charles, and Lee M. Kochems. "The North American Berdache." Current Anthropology, vol. 24, no. 4, 1983, pp. 443-470.

Davis, Jenny L. "More than just 'gay Indians': Intersecting articulations of Two Spirit gender, sexuality, and indigenousness". Queer Excursions: Retheorizing Binaries in Language, Gender, and Sex-

Indigenous Social Movements in the Americas uality. Lal Zimman, Jenny Davis, and Joshua Raclaw, editors. Oxford University Press. 2014, pp. 62-80

Driskill, Qwo-Li, Scott Morgensen, Brian Joseph Gilley, and Chris Finley, editors. Queer Indigenous Studies: Critical Interventions in Theory, Politics, and Literature. University of Arizona Press, 2011.

Driskill, Qwo-Li, Daniel Heath Justice, Deborah A Miranda, and Lisa Tatonetti. Sovereign Erotics: A Collection of Two-Spirit Literature. University of Arizona Press, 2011.

Edelman, Elijah Adiv. 2009. "The Power of Stealth: (In)Visible Sites of Female-to-Male Transsexual Resistance." Out in Public: Reinventing Lesbian/Gay Anthropology in a Globalizing World, edited by Ellen Lewin and William L. Leap, Blackwell, 2009, pp. 165-179. 
Epple, Carolyn. "Coming to Terms with Navajo Nádleehí: a Critique of "Berdache,' 'Cay,' 'Alternate Gender,' and 'Two Spirit'." American Ethnologist, vol. 25, no. 2, 1998, pp. 267-290.

Gilley, Brian. Becoming Two Spirit: Gay Identity and Social Acceptance in Indian Country. University of Nebraska Press, 2006.

Herdt, Gilbert, editor. Third Sex, Third Gender: Beyond Sexual Dimorphism in Culture and History. Zone Books, 1994.

Irvine, Judith, and Susan Gal. "Language Ideology and Linguistic Differentiation." Regimes of Language: Ideologies, Polities and Identities, edited by Paul Kroskrity, School of American research Press, 2000, pp. 35-84.

Jackson, Jason Baird. "Signaling the Creator: Indian Football as Ritual Performance Among the Yuchi and Their Neighbors". Southern Folklore, vol. 57, no. 1, 2000, pp. 33-64.

Jacobs, Sue-Ellen. "Berdache: A Brief Review of the Literature." Colorado Anthropologist, no. 2, 1968, pp 25-40.

Jacobs, Sue-Ellen, Wesley Thomas, and Sabine Lang. Two Spirit People: Native American Gender Identity, Sexuality, and Spirituality. University of Illinois Press, 1997.

Jolivette, Andrew. Indian Blood: HIV and Colonial Trauma in San Francisco's Two Spirit Community. University of Washington Press, 2016.

Morgensen, Scott Lauria. Spaces between Us: Queer Settler Colonialism and Indigenous Decolonization. First Peoples: New Directions in Indigenous Studies. University of Minnesota Press, 2011.

Rifkin, Mark. "The Erotics of Sovereignty". Queer Indigenous Studies: Critical Interventions in Theory, Politics, and Literature, edited by Driskill, Qwo-Li, Scott Morgensen, Brian Joseph Gilley, and Chris Finley, University of Arizona Press, 2011.

------. When Did Indians Become Straight?: Kinship, the History of Sexuality, and Native Sovereignty, Oxford University Press, 2011.

Roscoe, Will. "Bibliography of Berdache and Alternative Gender Roles Among North American Indians". Journal of Homosexuality vol. 14, no. 3-4, 1987, pp. 81-171.

----- . Changing Ones: Third and Fourth Genders in Native North America. St. Martin's, 1998. 
Indigenous Social Movements in the Americas

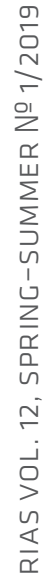

Roscoe, Will, and Gay American Indians (Organization). Living the Spirit: A Gay American Indian Anthology. St. Martin's Press, 1988.

Simpson, Audra. "On Ethnographic Refusal: Indigeneity, 'Voice' and Colonial Citizenship", Junctures, no. 9, 2007, pp. 67-80.

------. Mohawk Interruptus: Political Life Across the Borders of Settler States. Duke University Press, 2014.

Scudeler, June. "Gifts of Maskihkîy: Gregory Scofield's Cree Métis Stories of Self Acceptance." Queer Indigenous Studies: Critical Interventions in Theory, Politics, and Literature, edited by Driskill, Qwo-Li, Scott Morgensen, Brian Joseph Gilley, and Chris Finley, University of Arizona Press, 2011, pp. 190-210.

Tantonetti, Lisa. "Indigenous Fantasies and Sovereign Erotics: Outland Cherokees Write TwoSpirit Nations." Queer Indigenous Studies: Critical Interventions in Theory, Politics, and Literature, edited by Driskill, Qwo-Li, Scott Morgensen, Brian Joseph Gilley, and Chris Finley, University of Arizona Press, 2011, pp. 155-171.

------. The Queerness of Native American Literature. Indigenous Americas. University of Minnesota Press, 2014.

------. "Tales of Burning Love: Female Masculinity in Contemporary Native Literature." Indigenous Men and Masculinities: Legacies, Identities, Regeneration, edited by Anderson, Kim and Robert Alexander Innes, University of Manitoba Press, 2015, pp. 130-144.

Thomas, Wesley, and Sue-ellen Jacobs. 1999. "'[...] and We are Still Here': From Berdache to Two Spirit People." American Indian Culture and Research Journal, vol. 23, no. 2, pp. 91-107.

Whitehead, Joshua. 2018. "Why I'm Withdrawing From My Lambda Literary Award Nomination". The insurgent architects house. https://www.tiahouse.ca/joshua-whitehead-why-im-withdrawing-from-my-lambda-literary-award-nomination/. Accessed Oct. 12. 2018.

Williams, Walter. The Spirit and the Flesh: Sexual Diversity in American Indian Culture. Beacon, 1992.

Zimman, Lal. "'The Other Kind of Coming Out': Transgender People and the Coming Out narrative genre." Gender and Language, vol. 3, no. 1, 2009, pp. 53-80. 